\title{
O cinema romântico de Werner Herzog: aproximações entre o Romantismo Alemão e o conceito de Verdade Extática
}

\author{
Jéssica Pereira Frazão \\ Doutoranda; Universidade de São Paulo, São Paulo, SP, Brasil \\ jessicafrazao@usp.br \\ Regiane Regina Ribeiro \\ Doutora; Universidade Federal do Paraná, Curitiba, PR, Brasil \\ regianeribeiro5@gmail.com
}

\begin{abstract}
Resumo
O artigo parte da investigação acerca das semelhanças existentes entre o movimento intelectual conhecido como Romantismo Alemão e o conceito de Verdade Extática de Werner Herzog. Buscamos reconhecer, no cinema do cineasta, proposições de uma estética de influência romântica. Utilizamos, como metodologia principal, fontes diretas referentes à abordagem da Teoria dos Cineastas, isto é, além de fragmentos das obras fílmicas per se, também as entrevistas e declarações analisadas nos discursos de Werner Herzog a respeito da feitura dos filmes enquanto processos de criação. Os principais resultados obtidos diante da associação estabelecida apontam para: (1) indissociabilidade entre a tendência ao escapismo, inerentemente romântica, e os personagens herzoguianos; (2) fuga para a natureza como única opção restante; (3) momentos carregados da sensação de medo, arrepio e paralisia.
\end{abstract}

\section{Palavras-chave}

Romantismo Alemão. Verdade Extática. Werner Herzog. Cinema.

\section{Introdução}

0 intuito principal deste artigo é examinar os diálogos existentes entre o Romantismo alemão, ocorrido entre o final do século XVIII e o início do século XIX em países 
de língua alemã, e as acepções do diretor Werner Herzog referentes ao conceito de Verdade Extática. Aproximações herzoguianas dessa natureza promovem uma leitura sobre como são internalizadas as ideias de sublime e de êxtase no cinema do cineasta em função de sua proposta autoral de verdade fílmica. Ao mostrar proximidade com os trabalhos tanto de filósofos como Longino e Immanuel Kant, quanto de artistas como Achim von Arnim e Caspar David Friedrich, Herzog nos traz subsídios importantes para observarmos traços de uma visão de mundo romântica nas suas narrativas imagéticas.

Propomos evidenciar um modo de compreender o cinema à luz das obras fílmicas Sinais de vida (1968) e O grande êxtase do entalhador Steiner (1974), visto que reforçam, na nossa concepção, caracterizações do Romantismo ligadas principalmente ao escapismo, ao individualismo e ao culto à natureza e imaginação como fonte de inspiração. Características que outrora influenciaram os artistas românticos são percebidas, na visão de Walter Benjamin (1997), pela inclinação romântica da beleza, da verdade e da ação. Uma abordagem analítica e comparativa dos filmes de Herzog, assim como fragmentos de textos reunidos na Declaração de Minnesota: verdade e fato no Cinema Documentário (HERZOG, 1999), no discurso publicado Sobre o absoluto, o sublime e a Verdade Extática (HERZOG, 2010), e nas entrevistas e depoimentos em diferentes suportes midiáticos, possibilita maior familiarização com o seu processo de criação cinematográfica observável na mise-en-scène.

A Verdade Extática tem, em essência, um locus privilegiado de acesso à natureza pelo escape. 0 termo é mencionado pelo próprio diretor como uma condição de verdade inimiga do meramente factual e que deve nos remeter à essência vinda do êxtase no mesmo sentido da palavra em grego ekstasis (ir para fora de si mesmo). Encontramos ancoragem na assertiva de que o Romantismo Alemão é oportuno no acesso à Verdade Extática, principalmente no que diz respeito ao uso criativo de elementos intrinsecamente fílmicos. Sendo parte do processo criativo de cada realizador cinematográfico, esse acervo inventivo do qual os cineastas fazem uso é uma confirmação de que, assim como sugeria Deleuze (1999, p. 6), “[...] existem idéias no cinema que só podem ser cinematográficas”.

Quando Jacques Aumont, na obra As teorias dos cineastas (2004), concebe a tese de que "[...] o cineasta é um homem que não pode evitar a consciência de sua arte, a reflexão sobre seu ofício e suas finalidades, e, em suma, o pensamento" (AUMONT, 2004, p. 7), verificamos como ele aponta para as formas diversas de observar a reflexão advinda desses artistas/diretores. Werner Herzog, a seu modo, poderia facilmente se adaptar ao grupo de cineastas indicados pelo teórico como criadores de conceitos que buscam uma resposta ao 
problema do real. A forma de aplicação de determinada invenção conceitual vai depender, assim, da "[...] colaboração entre o artista, que dispõe de uma linha principal - seu projeto e o real, que fornece a surpresa permanente dos encontros" (AUMONT, 2004, p. 52).

\section{0 conceito herzoguiano de Verdade Extática}

A explanação do conceito de Verdade Extática se baseia no mapeamento prévio das fontes diretas, isto é, nas entrevistas e declarações de Werner Herzog, considerando sobretudo os enunciados do cineasta acerca da sua noção de verdade fílmica e da própria arte e ofício. Iniciaremos fazendo menção à Declaração de Minnesota: verdade e fato no Cinema Documentário, texto escrito e publicado por Herzog em 1999, sendo essa a primeira vez em que o público teve acesso ao termo Verdade Extática. Um dos doze postulados da declaração, ao se referir ao vocábulo, estabelece que "Existem camadas mais profundas de verdade no cinema, e existe algo como uma verdade poética, extática. É algo misterioso e elusivo, que só pode ser alcançado por meio de fabricação, imaginação e estilização." (HERZOG, 1999, tradução nossaํㅜ).

A primeira leitura aberta desse conteúdo recebeu, em um primeiro momento, aprovação do público presente no Walker Art Center em Minnesota (CRONIN; HERZOG; 2014). Entretanto, alguns teóricos encontraram dificuldade de compreensão, pois viam a Verdade Extática como uma forma de apropriação de certas convenções e maneiras de dizer a verdade já expostas em documentários anteriores (AMES, 2012). Contestando respostas negativas, Herzog assumiu que a declaração é de sua própria autoria, divagações que lhe vieram à mente de madrugada em um quarto de hotel, enquanto assistia pornografia na televisão. As cenas, segundo ele, apresentavam uma verdade nua, muito mais profunda do que o filme de natureza apresentado anterioriormente, sobre animais harmoniosos e encantadores do Serengeti (região da África oriental).

Um exame mais atento da declaração (HERZOG, 1999) sugere que o ponto culminante é a natureza estilizada de apresentação do filme, característica contrária a qualquer aspecto de representação fílmica não-participativa, observativa, estilo "mosca na parede". Em outras palavras, deve ser a dimensão poética do trabalho fílmico a se sobressair, desprestigiando os aspectos factuais, políticos e sociais de representação do

\footnotetext{
${ }^{1}$ No original: "There are deeper strata of truth in cinema, and there is such a thing as poetic, ecstatic truth. It is mysterious and elusive, and can be reached only trough fabrication and imagination and stylisation".
} 
mundo histórico. Este elemento poético, a essência autônoma da sua verdade aparece, quando, na última cena de $O$ grande êxtase do entalhador Steiner (1974), há um trecho do conto do escritor suíço Robert Walser sobreposto às imagens. Herzog é enfático ao relacionar sua Verdade Extática àquilo que as pessoas sentem quando leem um bom poema.

Ainda de acordo com a declaração (HERZOG, 1999), a Verdade Extática é o oposto das proposições da corrente cinematográfica conhecida como Cinema Vérité, já que proclama que estas são representações factícias que não trazem iluminação nem verdade, apenas mostram fatos primitivos e superficiais. Novamente, Ames (2012) critica Herzog e aponta para a confusão que ele faz sobre a escola originada por Jean Rouch. Faz sentido acreditar que o discurso de Herzog se assemelha muito mais aos praticantes do Cinema Direto do que aos seguidores do Cinema Vérité, porém não há consenso na terminologia, inclusive entre os estudiosos do cinema².

Para o diretor, a explicação do que vem a ser a Verdade Extática será obtida pela diferenciação daquilo que oferece o Cinema Vérité e pela insistência na aproximação com a poesia, literatura e música enquanto substâncias participantes da verdade do filme. Seu ponto principal desvincula fato e verdade enquanto uma condição, reforçando que "Os fatos criam normas, e a verdade, iluminação" (HERZOG, 1999, tradução nossa³).

Finalmente, o realizador menciona em entrevista que seu cinema é feito "[...] de joelhos e coxas, de estar preparado para trabalhar vinte horas por dia" (CRONIN; HERZOG, 2014, p. 114, tradução nossa4). Herzog (2014) defende constantemente que suas obras emanam um sentido físico (ele usa o termo atlético), em que a presença do corpo físico exerce função primordial tanto de sua equipe quanto de seus atores. Esta configuração corpórea que fala está “[...] na fervorosa crença do diretor de que o cinema está conectado, em um nível fundamental, com a fisicalidade da experiência incorporada por parte do personagem fílmico e do cineasta" (WRIGHT, 2016. p. 83, tradução nossa5). Compreendemos essa asserção a partir de dois posicionamentos. De um lado, o diretor elege e enaltece a experiência física, via circunstâncias de produção. Do outro lado, o êxtase advindo da sua verdade só acontece no momento em que o corpo se despreende pela experiência do

\footnotetext{
2 De acordo com Hall (2013), o termo Cinema Vérité começou a ser utilizado para designar as escolas (francesa e americana) que seguiam a linha de corrente documentária inventada por Jean Rouch. Alguns teóricos do cinema utilizam o termo Cinema Vérité apenas para se referirem à escola francesa e Cinema Direto para se referirem à escola americana. Entretanto, é possível encontrar muitos estudiosos (a exemplo de Robert C. Allen, A. William Bluem, Noël Carroll, Stephen Mamber, Bill Nichols, Thomas Waugh) que utilizam o termo Vérité para ambas.

3 No original: "Fact creates norms, and truth illumination".

4 No original: "[...] from knees and thighs, from being prepared to work twenty-hour days".

${ }^{5}$ No original: “[...] is the director's fervent belief that cinema is connected, at a fundamental level, with the physicality of embodied experience on the part of both the filmic character and the filmmaker".
} 
sensível. Para Ames (2012, p. 20, tradução nossa6), "[...] êxtase, consequentemente, se torna não apenas um jeito de abandono do corpo, mas também uma forma de abraçá-lo".

\section{Em busca de uma estética romântica}

O verbete Romantismo do Concise Oxford Dictionary of art terms (2010) admite que “a natureza, vista anteriormente como parte do ambiente do homem, agora era vista como força elementar, inspirando nos homens reações emocionais, bem como um interesse concomitante em pinturas de natureza de todos os tipos" (CLARKE, 2010, p. 215, tradução nossa ${ }^{7}$ ). A escolha de associar o universo artístico de Herzog ao Romantismo Alemão não é arbitrária. A potência da natureza é critério fundamental na filmografia herzoguiana, como veremos.

O livro Forgotten Dreams: Revisiting Romanticism in the Cinema of Werner Herzog (2016), de Laurie Rohn Johnson, autora e professora do Departamento de línguas e literaturas germânicas da Universidade de Illinois, é uma referência em estudos que vinculam Herzog a uma estética romântica. Johnson expressa a crença de que os filmes de Herzog são “[...] como um legado do Romantismo" (JOHNSON, 2016, p. 2, tradução nossa8). Ela aponta que a devoção do cineasta com o êxtase da verdade recai sobre a intenção dos pré-românticos (do final do século XVIII) de aproximar seus trabalhos a artefatos, a fabricações e à natureza. A compreensão do mundo via subjetividade era a proposição dos românticos, e a arte, sua forma de expressão. Uma estética romântica surge para apresentar uma inovação na reflexão sobre a sociedade europeia e para pensar uma nova Weltanschauung9 , contrária à estética iluminista de primazia da razão.

Nesse sentido, a estética romântica que defendemos é constituida em grande parte pela relação com a paisagem, indicando o ponto de partida e de chegada de uma expressão artística romântica, visto que o mundo subjetivo dos artistas desse período é, ao mesmo tempo, o criador e o mundo que este criou (PRAGER, 2007). 0 mais alemão dos cineastas da

\footnotetext{
${ }^{6}$ No original: "[...] ecstasy, consequently, becomes not just a way of abandoning the body but also a way of embracing it".

7 No original: "Nature, hitherto viewed as an ordered part of man's environment, was seen as an elemental force inspiring an emotional reaction in man and a concomitant interest in landscape painting of all types".

${ }^{8}$ No original: "[...] as a legacy of romanticism".

${ }^{9}$ Termo em alemão para visão de mundo de determinado indivíduo, grupo ou sociedade.
} 
Alemanha, assim como o consagrou Lotte Eisner ${ }^{10}$, demonstra tendência em escolher personagens e paisagens que facilmente o enquadrariam enquanto artista romântico: os protagonistas herzoguianos estão em uma constante busca do eu (self), uma vez que, na coletividade em que se encontram, há deslocamento e solidão. 0 deslocamento os faz fugir para paisagens pouco exploradas (encontro com o criador), que por intermédio da sensibilidade e pelas condições-limite nessa relação com a natureza, procuram alcançar respostas para sua existência, atingindo o nível do sublime. 0 sublime se dá como consequência da nossa percepção de mundo.

Romantismo é frequentemente associado com o sublime, um momento único de irresistível admiração, melhor do que com relação ao belo, uma experiência mais prazerosa e até mais reconfortante que pode ser repetida. Mas os filmes de Herzog nos encorajam a explorar a interseção dos dois e também a relação entre singularidade e repetição que eles implicam. As frequentes distâncias (por uma perspectiva ocidental) e as configurações perigosas nos filmes de ficção e documentários de Herzog, podem ser interpretadas como psico-topografias, nas quais os aspectos da vida interior do protagonista (ou espectador) são visíveis em bela e/ou sublime natureza (JOHNSON, 2016, p.10-11, tradução nossa ${ }^{11}$ ).

Outro exame mais atento dessas características românticas herzoguianas fundamenta-se na ocasião de sua fala em Milão (Itália) em 2007, precedente de exibição do seu filme Lições da escuridão (1992). Intitulado Sobre o absoluto, o sublime e a Verdade Extática (HERZOG, 2010), esse discurso, oito anos depois da feitura da Declaração de Minnesota (HERZOG, 1999), demonstra alguns novos elementos não mencionados anteriormente pelo diretor, sendo, portanto, a menção aos termos filosóficos "absoluto" e "sublime" evidenciados pela primeira vez. Com isso, Herzog atenta-se, agora mais diretamente, para a sublimação das maneiras de ler o real na sua criação artística, tanto pelo

\footnotetext{
10 Lotte Eisner (1896-1983) tem importância fundamental na história do cinema porque, além de ter sido uma das primeiras mulheres críticas de cinema, escreveu obras clássicas como A tela demoníaca (1952), clássico indispensável para quem se interessa pelo Expressionismo Alemão. Sendo uma autoridade em cinema alemão, aconselhou e auxiliou os novos cineastas do Jovem Cinema Alemão (Junger Deutscher Film). Um dos cineastas mais próximos de Eisner era justamente Werner Herzog, considerada por ele sua mentora.

11 No original: "Romanticism is often associated with the sublime, a unique moment of overwhelming awe, rather than with the beautiful, a more pleasurable and even comforting experience that may be repeated. But Herzog`s films encourage us to explore the intersection of the two and also the relationship between singularity and repetition that they imply. The often far-flung (from a Western perspective) and dangerous settings in Herzog`s feature and documentary films can be interpreted as pycho-topographies, in which aspects of a protagonists (or spectators) inner life are made visible in beautiful and/or sublime nature".
} 
isolamento dos personagens quanto pela busca das suas "imagens adequadas", ou seja, o olhar virgem que sempre apresenta algo pela primeira vez.

O diretor deixa claro que, apesar do seu interesse, não está apto a discorrer sobre o absoluto, apenas menciona que o assunto continua a ser um dilema para várias áreas do saber, como a Filosofia, a Religião e a Matemática. Em relação ao sublime, é comentando os escritos de Immanuel Kant (1724-1804) e os atribuídos a Dionísio Longino (Séc I) que ele se sente mais confortável, como se tais escritos filosóficos fossem um testemunho ou confirmação daquilo em que acredita. A explicação se baseia nas experiências extáticas, configuradas no momento em que se atinge o nível do sublime, no sentido de elevação acima da natureza. Herzog utiliza o sentido estético do sublime comentado por Kant (2008) na sua Crítica da faculdade do juízo, obra intermediadora capaz de mesclar o juízo advindo do conhecimento (entendimento) e da razão. Simplificadamente, a estética kantiana demostra que o ato de julgar está diretamente relacionado à dor e ao prazer. Esses preceitos foram integrantes de uma estética germânica romântica, nos quais o cineasta se baseia.

Na contramão de Kant, Longino tem a predileção de Herzog no que tange à especificidade de qualificar o sublime, uma vez que o expõe exemplificando-o. De maneira mais descomplicada, volta-se para uma práxis de que necessita o diretor diante de um contexto imagético. Pela obra Do Sublime (LONGINO, 1996), o filósofo foi o primeiro a associar o termo às conceituações de variante estética, somando-o às já existentes de belo e de grotesco. Ele argumenta que o sublime se constitui não pela ordem e pela estruturação lógica, mas sim pelo caos, pelo desequilíbrio e pelo distanciamento, que causam espanto, comoção e admiração.

Todos os personagens herzoguianos condizem com a asserção de Longino (1996) do encontro com o sublime: reconhecidamente deslocados, chamados de loucos e pouco compreendidos, eles almejam o extraordinário e dentro das suas ambições, são sempre relembrados pela natureza de suas circunstâncias humanas diminutas. Ainda assim, elevamse pela ausência do medo e pela evocação da ideia de êxtase. 0 êxtase imagético em Herzog assemelha-se à noção de êxtase em Longino principalmente por adentrar-se em um estado mais elevado até "sair de si mesmo", um elevar-se acima da natureza, revelado pela veracidade daqueles que alcançam o sublime. As menções ao tipo de autor/artista/teórico que em geral agrada a Herzog e que ele menciona mais frequentemente (suas referências visuais e literárias), parecem-nos confirmar, cada vez mais, o cruzamento de uma poética romântica presente no seu trabalho com um discurso romântico de que faz uso. 
Verdade, para Herzog, não consiste no mundano. É uma descoberta pessoal na medida em que é um evento estético. A procura e a descoberta de algo além de nós mesmos resulta na "verdade extática", que é, eu acredito, uma mistura de idealismo e romantismo. A "verdade" herzoguiana não é superficial; É algo fora do nosso ser consciente, uma transcendência que torna o mundo extático (VERRONE, 2011, p. 189, tradução nossa ${ }^{12}$ ).

Com efeito, falar de sublime reflete fortemente, em termos estéticos e narrativos da cinematografia herzoguiana, a forte aproximação da paisagem versus personagem. Diversos autores já mencionaram a pertinência da paisagem no trabalho do cineasta, tomadas não como plano de fundo ou mero instrumento de apoio, e sim como meio de descortinar imagens de lugares nunca antes visitados. Seu acervo imagético, envolvendo todos os cinco continentes e mais de vinte diferentes países, oferece, na concepção herzoguiana, imagens puras e absolutas (CRONIN; HERZOG, 2014).

Assim como nas obras artísticas de Caspar David Friedrich, analisado mais à frente nesta investigação, a paisagem herzoguiana trabalha com parâmetros do Romantismo Alemão tendo em vista "[...] a prática da estetização e interior psicológico em termos de paisagem" (AMES, 2009, p. 51, tradução nossa13), ou uma "[...] inclinação para usar a paisagem assim como uma representação externa das complexidades da psicologia interna" (PRAGER, 2010, p. 94, tradução nossa14). Nesse contexto, seus filmes "ópticos" efetivam na natureza o começo e o final das narrativas, que sozinhas já são capazes de causar emoções no espectador, mas que são acentuadas pelo envolvimento do personagem nessa relação. Em síntese, a paisagem herzoguiana é capaz de dar-nos dados reveladores, que vão além das experiências superficiais, e se alimenta, por um lado, da ligação com o medo do desconhecido, da morte e do perigo e, por outro lado, da obsessão de suas personagens em atingir picos de adrenalina que extrapolam suas condições humanas (GANDY, 2012).

Seus filmes raramente se detêm nas paisagens urbanas, que pertencem ao cotidiano do público cinematográfico, sendo, portanto, facilmente

\footnotetext{
12 No original: "Truth, for Herzog, does not consist in the mundane. It is a personal discovery inasmuch as it is an aesthetic event. The search and discovery for something beyond ourselves results in the 'ecstatic truth,' which is, I believe, a commingling of idealism and romanticism. Herzog's 'truth' is not superficial; it is something outside of our conscious being, a transcendence that renders the world ecstatic".

${ }^{13}$ No original: "[...] the practice of aestheticizing the psychological interior by means of landscape".

${ }^{14}$ No original: "[...] inclination to use the landscape as an external representation of the complexities of internal psychology".
} 
identificáveis por ele: Herzog vai buscar nas selvas, nos desertos, nas montanhas escarpadas, nas geleiras imagens inéditas, que o espectador possa reconhecer como reais, mas que lhe sejam até então desconhecidas A elas acrescenta, ainda, uma montagem e uma música de função subliminar e hipnótica, a fim de transportar o espectador, menos pela via do convencimento que pela da adesão, para um universo primordial, no qual estaria contida a "verdadeira" realidade. (NAGIB, 1991, p.21)

Não obstante, o filme "óptico" não é apreciador de qualquer paisagem. A natureza enquadrada pelas lentes herzoguianas é, numa primeira instância, física e material, não metafísica nem transcendental. O diretor, utilizando representações do mundo físico, materializa e transforma tais paisagens em imagens cinematográficas (AMES, 2009), uma vez que essas paisagens funcionam como estados da mente (PAGANELLI, 2010). De certo modo, as paisagens em Herzog também entregam mais do que fotografias de natureza, são imagens estáticas na mesma hora em que são sons e imagens em movimento. Com propriedades visuais sobrepostas às verbais, destacam aspectos estéticos singulares e dão ênfase à autoria, revelando uma visão de mundo ao mesmo tempo referencial e antireferencial 15 , de modo a posicionar o diretor dentro da sua produção e memória cultural, como propõe Simon Schama (1995).

Pela importância da paisagem em sua relação com o personagem como vínculo primordial na representação da Verdade Extática, percebemos que as imagens são mais que frames de vulcões em erupção, picos de montanhas, florestas tropicais ou águas caudalosas dos rios. Expressam posicionamentos culturais, sociais e políticos e demandam interação e leitura atenta para suas diversas mensagens extra fílmicas e metáforas. Essas imagens explicam o mundo de uma maneira particular, capturadas por aqueles que "andam a pé" (CRONIN; HERZOG, 2014), como um peregrino. A verdade é uma expressão poética, “[...] é possível alcançá-la através de visão, estilo e técnica" (HERZOG, 2010, tradução nossa ${ }^{16}$ ).

Desse modo, defendemos que a Verdade Extática é uma experiência estética romântica (fuga para a natureza como única opção; deslocamento do Homem da sociedade de que faz parte; vivência do amedrontamento, da imobilidade e do risco), tendo por base postulados filosóficos que relatam uma emoção dominante do sublime, ressaltada pelo

\footnotetext{
15 Exemplo disso é o uso de Grandes Planos Gerais (GPG) em momentos de contraste junto ao personagem. São paisagens que lembram sua infância na Baviera porque parecem inabitáveis, de difícil acesso, novas para o olhar do espectador, e é justamente essa novidade desenvolvida entre outros elementos fílmicos, como a trilha musical extra-diegética, que diferenciam estas paisagens daquelas vistas nos "postais turísticos". São fotografias posicionadas para trazer-nos a sensação de altitude por uma vista panorâmica, no mesmo momento em que distancia e aproxima os objetos.

16 No original: "[...] one attains it through vision, style, and craft".
} 
abarcamento do êxtase, um sentimento carregado de medo, sensação de arrepio e paralisia que sentem os personagens, ou, em outras palavras, uma ocupação pelas coisas divinas.

\section{Aspectos de um cinema romântico em Sinais de vida (1968) e $O$ grande êxtase do entalhador Steiner (1974)}

Impossível falar dos filmes de Herzog sem mencionar o legado que o Cinema Novo Alemão ${ }^{17}$ deixou para os períodos posteriores de produção cinematográfica, seja pela sua forma impactante, seja pela liberdade de brincar com fronteiras entre o documental e o ficcional, entre realidade, estilização e excesso de romantismo, configurando um estilo cinematográfico original e audacioso, pouco conhecido até então. Esta cinematografia importa porque claramente representa o Zeitgeist ${ }^{18}$ de um período marcado por mudanças em vários aspectos da sociedade alemã do pós-guerra (décadas de 1960 e 1970). Na busca incessante de uma nova identidade alemã, ao invés de preservar o passado, tentou-se desconsiderá-lo ou, no mínimo, reconstruí-lo, e pela primeira vez, atentou-se para questionamentos de grupos minoritários, como gays e lésbicas, mulheres e grupos étnicos.

Logo na primeira película ficcional de Werner Herzog, Sinais de vida (1968) (Figura 1 e 2), filme-marco que o associou definitivamente ao Cinema Novo Alemão, a conexão com o Romantismo se configura em sentido narrativo, visto que o roteiro foi inspirado no conto Der Tolle Invalide auf dem Fort Ratonneau, escrito por Achim von Arnim (1781-1831), poeta, escritor e uma das figuras centrais do Romantismo Alemão, ao lado de Clemens Brentano e Joseph von Eichendorff. 0 diretor admirava o trabalho de Arnim e buscou, nesse conto, inspiração para seu filme. Cheio de experimentação, a película estava propensa ao exercício da técnica e foi a primeira grande experiência do cineasta no roteiro, na direção e na produção de um longa-metragem, com baixo orçamento e com equipe minúscula, além de figurar muito próximo da linguagem documental, apesar de ficcional. A ilha de Kos (Figura 1), com suas praias, ruínas e castelos foi escolhida como locação, em certa medida, devido às viagens que o diretor fez à região quando tinha quinze anos, seguindo os passos que seu avô Rudolf Herzog traçou anos antes como arqueólogo.

\footnotetext{
17 Esse período de produção cinematográfica trouxe entrelaçamentos e debates sobre identidade e memória, romantismo e realismo, ficção e documentário e fato e realidade, demarcando o lugar de diretores como Fassbinder, Herzog, Wenders, Syberberg, Schlöndorff e Kluge no universo do Cinema de Autor (Autorenfilm).

18 Zeitgeist é um conceito utilizado na filosofia alemã dos séculos XVIII e XIX, traduzido por "espírito da época" "espírito do tempo". Em outras palavras, o termo Zeitgeist remete a um conjunto tanto intelectual quanto cultural de determinada época/tempo.
} 
Figura 1 - Fotograma de Sinais de vida em 06:33. Direção: Werner Herzog.

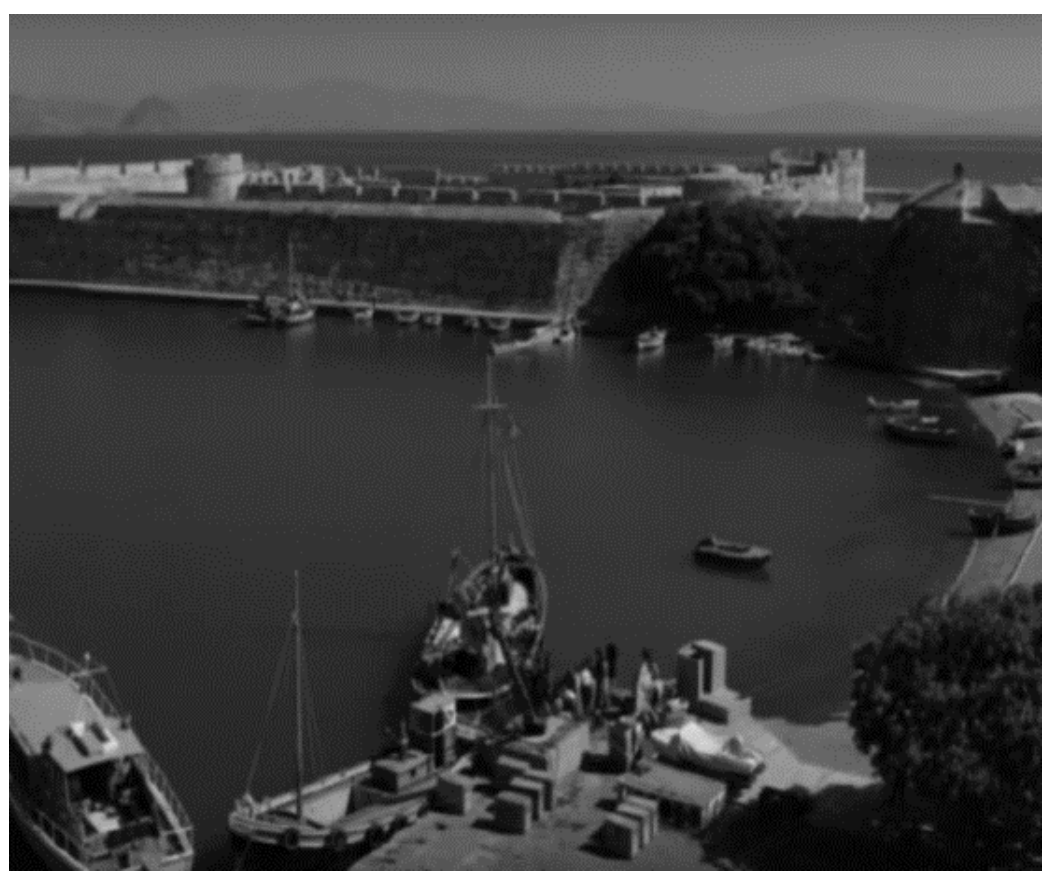

Fonte: reprodução de Sinais de vida (1968).

Figura 2 - Fotograma de Sinais de vida em 01:06:37. Direção: Werner Herzog.

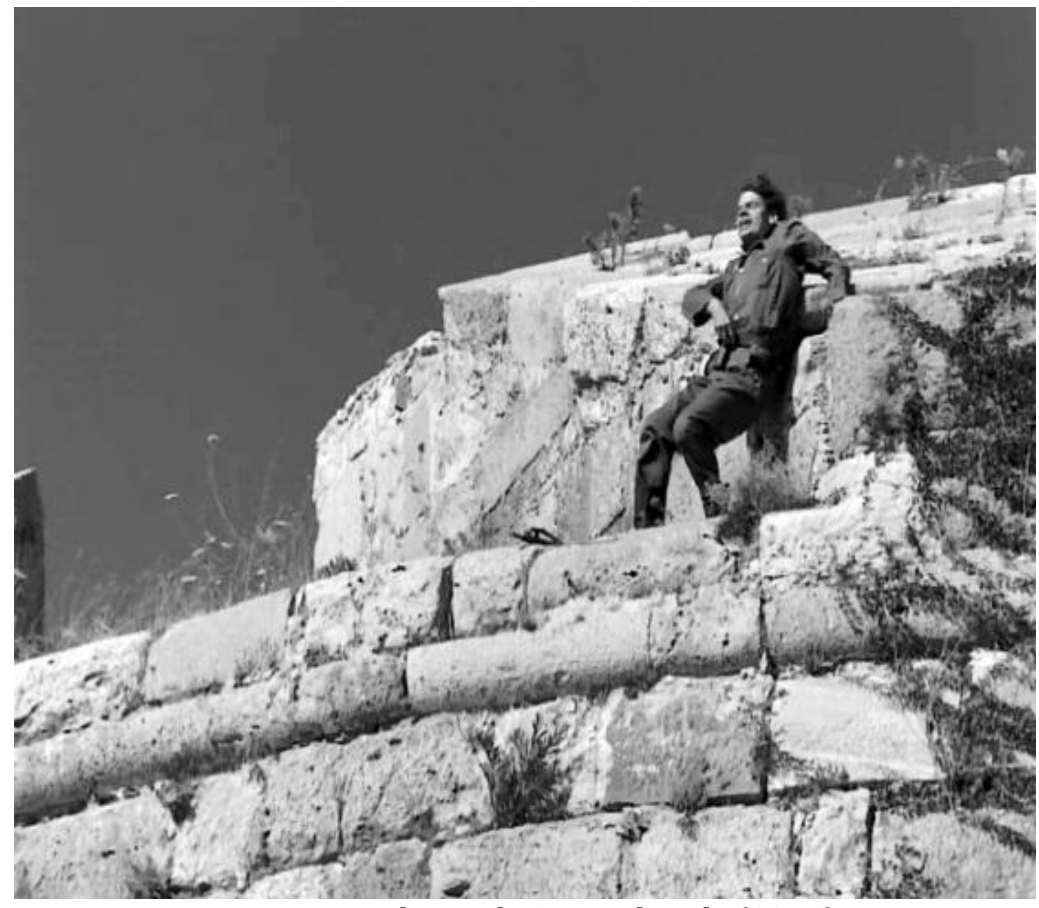

Fonte: reprodução de Sinais de vida (1968). 
Em ambas as histórias, o personagem principal fica alucinado e se tranca no forte, ameaçando explodir toda a cidade com fogos de artifício (Figura 2). Na história de Arnim, a paisagem é a cidade de Marseille, representada por Herzog pela ilha de Kos. Vemos que a loucura e a presença do mal são fortemente sublinhadas no conto e no filme. Os aspectos de maior identificação do conto no filme são a presença do fogo (em forma de fogos de artifício), das esposas dos personagens principais e da quebra de ligação destes com a sociedade, voltando-os para um individualismo romântico que encontra abrigo no forte, envolto da natureza. Basicamente, são "[...] os ingredientes românticos que Herzog assume resolutamente para transpor num contexto real" (NAGIB, 1991, p.77). Porém, acreditamos que Herzog o faz com um estilo muito próprio e desvinculado de Achim para além dos elementos citados, visto que o filme beira o documental, tamanha a tentativa de desmistificação.

Semelhantemente, Herzog assumiu em entrevista ter bastante afinidade (CRONIN; HERZOG, 2014) por Caspar David Friedrich (1774-1840), considerado o mais importante artista do período romântico, exímio pintor de paisagens. Friedrich, segundo Herzog (2014), é o único desta escola filosófica e artística de quem o diretor assumiu ter algum conhecimento, ainda que, como vimos, também tenha lido e considerado o conto de Achim von Arnim. Mais do que tê-la admirado, Herzog pode ter feito uso da forma paisagística trabalhada por Friedrich em alguns de seus filmes, ainda que indiretamente. Podemos dizer com mais afinco que o desconhecido é temática recorrente para estes dois artistas, tanto que de acordo com Johnson (2016, p. 19, tradução nossa ${ }^{19}$ ), da mesma forma que Friedrich, "Herzog deseja produzir imagens que ainda não tenham sido vistas".

As cenas de saltos em esqui em $O$ grande êxtase do entalhador Steiner (1974) (Figura 3), e a pintura Caminhante sobre o mar de névoa (1818), de Caspar David Friedrich (Figura 4), fazem analogias de uma paisagem vista como evocação de sublimidade. Ressaltase a poesia existente na natureza devido às montanhas, nevascas, cerração e à altitude. Nessas obras, tanto Herzog quanto Friedrich orientam seu público a pensar o misticismo existente naquela paisagem, posicionando-a como o próprio mundo natural. 0 vale de Planica (região apresentada no documentário) é montanhoso como a pintura, e neve e neblina parecem distanciar o personagem do resto do mundo.

${ }^{19}$ No original: "[...] Herzog wishes to produce images that have not yet been seen". 
Figura 3 - Fotograma de O grande êxtase do entalhador Steiner em 01:06:37. Direção: Werner Herzog

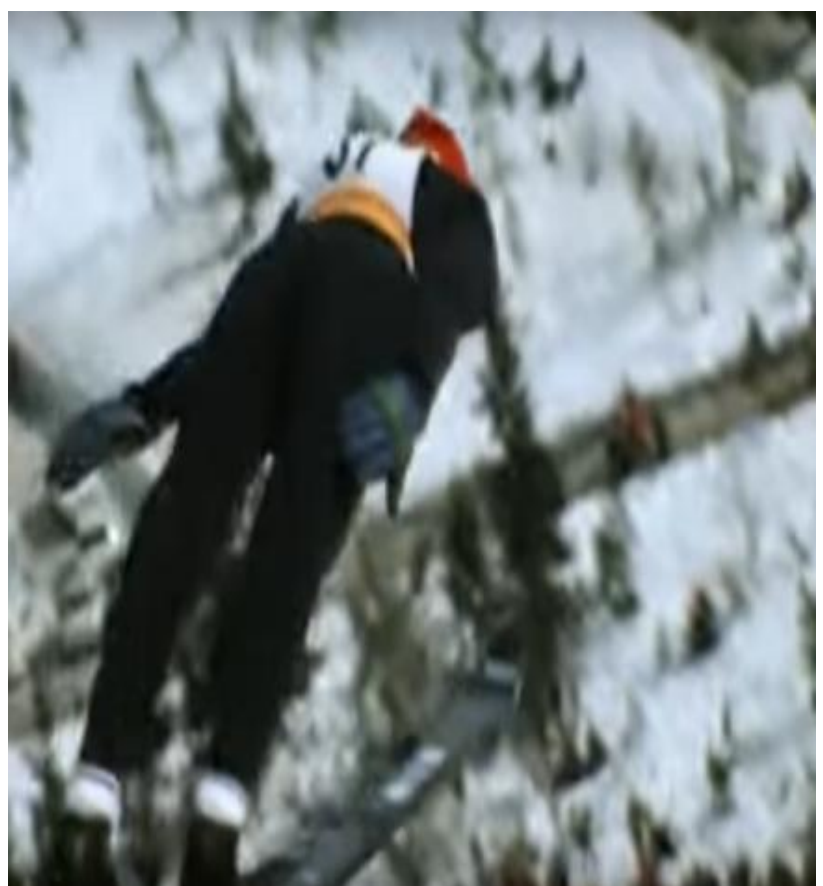

Fonte: reprodução de O grande êxtase do entalhador Steiner (1974).

Figura 4 - Pintura de Caspar David Friedrich

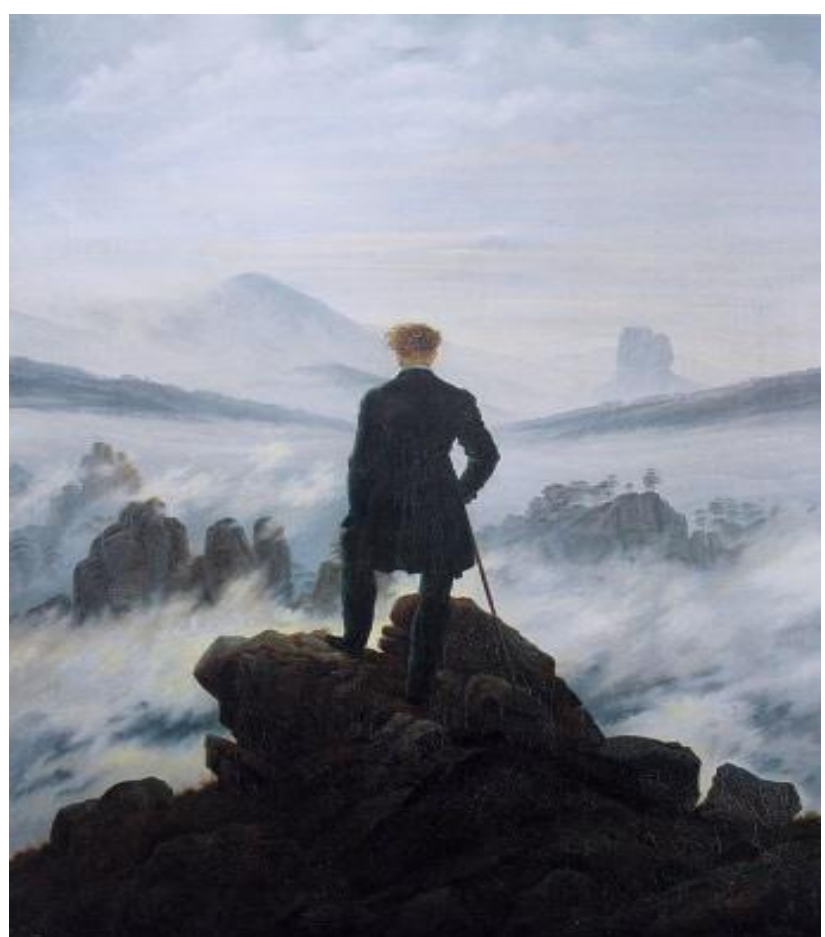

Fonte: Der Wanderer über dem Nebelmeer (1818). 
Porque repleta de elementos realísticos, a combinação de componentes como imaginação e realidade traz verossimilhança para a situação e faz sentido para a audiência, dado o uso de luz e de perspectiva, tornando-se atemporal (JOHNSON, 2016). 0 personagem é completamente envolto da paisagem, mas não sabemos ao certo se é a natureza que domina o homem, ou se é o homem que domina a natureza, já que da mesma forma que estes elementos se misturam e se aproximam, eles também se distanciam.

A partir dos princípios da estética romântica de paisagem, a presença humana se dá de forma solitária, e contemplar a região alpina tendo como ponto de vista a grandiosidade do lugar só é possível devido à altitude atingida. Ainda que na obra de Friedrich se trate de um viajante e na de Herzog, de um esquiador (ou daquele que voa), a imensidão da natureza traz a sensação de perda no infinito e consequentemente, de aproximação com o sublime. A incansável busca do personagem Steiner de voos mais altos também pode ser interpretada como um ideal romântico de insistência.

É expansiva a natureza dual nas obras de arte dos românticos, situação também percebida na filmografia herzoguiana. De acordo com Johnson $(2016$, p. 13, tradução nossa ${ }^{20}$ ): "A capacidade das pinturas românticas de conectar conhecido e não conhecido, observador e observado, êxtase e movimento, imagem e narrativa, é relacionável à tendência no pensamento romântico de construir relações conceituais e estéticas em termos de reciprocidade". Reciprocidade é, portanto, um dos Motive da estética romântica. A própria busca do eu, e no caso de Herzog, a identificação com seus personagens enquanto seu self, também opera por essa dualidade.

Outras aproximações com tradição romântica alemã, em outros filmes de Herzog, também são concebíveis, como em Aguirre, a cólera dos deuses (1972), $O$ enigma de Kaspar Hauser (1974), Stroszek (1977), Fitzcarraldo (1982) e até mesmo nos mais recentes como Homem urso (2005). Algumas dessas indagações foram, inclusive, apresentadas com primazia em livro já citado de Laurie Johnson (2016). Porém, detemo-nos na análise daquelas obras fílmicas em que observamos um confronto direto com os trabalhos de Achim von Arnim e Caspar David Friedrich, assumidamente conhecidos por Herzog em entrevistas.

\footnotetext{
${ }^{20}$ No original: "Romantic painting`s capacity for connecting knowing and not-knowing, viewer and viewed, stasis and motion, and image and narrative, is related to the tendency in romantic thought to construct conceptual and aesthetic relations in terms of reciprocities".
} 


\section{Considerações finais}

A filmografia herzoguiana é, como vimos, um exemplo aplicável de expressão artística reconhecida pela ótica que prioriza a estética romântica alemã. 0 conceito autoral herzoguiano de Verdade Extática nos auxilia nessa discussão. Ao refletir sobre a questão: “0 que torna um filme extático?”, Prager (2007), por exemplo, acredita ser a indução de uma condição sem a necessidade de palavras. No nosso ponto de vista, um filme extático enfatiza imageticamente a contemplação (do mundo sensitivo), pelo envolvimento do corpo com aquilo que é o sublime, isto é, com aquilo que está acima do humano, em um momento único de irresistível admiração.

Sinais de vida (1968) e O grande êxtase do entalhador Steiner (1974) são amostras de um cinema que aponta para essas inclinações românticas não apenas esteticamente, mas como um conjunto de atributos de dimensão narrativa, principalmente pela ótica do escapismo e fuga para e da natureza como validação. A Verdade Extática, nessas obras, é representada por momentos carregados de medo, sensação de arrepio e paralisia que experimentam os personagens quando se arriscam. São filmes capazes de conjugar, cinematograficamente, características de veneração da natureza e da imaginação pelo fascínio e de instituir o desvio e o individualismo como substancialidade de composição.

Na nossa visão, o apelo ao sensível torna-se notório quando colocado em tensão com a lógica formal enquanto demonstrativa da verdade. Atentar para o processo criativo do cineasta Werner Herzog por sua base romântica, com Achim von Arnim e Caspar David Friedrich, e filosófica, com Kant (2008) e Longino (1996), sustentou um olhar mais analítico sobre o que representaria seu cinema romântico, cuja força autoral não poderia ser ignorada. Dessa forma, a interpretação que fizemos de uma estética romântica alemã ter influenciado a idealização do êxtase da verdade herzoguiano tem suporte na ótica do sublime, objeto (da natureza) e essência primeira do romantismo alemão.

\section{Financiamento}

A pesquisa contou com o apoio da Coordenação de Aperfeiçoamento de Pessoal de Nível Superior (Capes). 


\section{Referências}

AMES, Eric. Ferocious Reality: Documentary according to Werner Herzog. Minneapolis: University of Minnesota Press, 2012.

AMES, Eric. Herzog, Landscape, and Documentary. Cinema Journal,, Austin, v. 48, n. 2, p. 4969, winter 2009.

AUMONT, Jacques. As teorias dos cineastas. Campinas: Papirus, 2004.

BENJAMIN, Walter. Romantik, 1913. In: BENJAMIN, Walter et al. (org.). Gesammelte Schriften: supplement II. Frankfurt: Suhrkamp, 1997.

CLARKE, Michael. The Concise Oxford Dictionary of Art Terms. 2. ed. Oxford: Oxford University Press, 2010.

CRONIN, Paul; HERZOG, Werner. Werner Herzog - A Guide for the Perplexed:

Conversations with Paul Cronin. London: Faber \& Faber, 2014.

DELEUZE, Gilles. 0 ato de criação. Folha de São Paulo, São Paulo, 27 jun. 1999.

FRIEDRICH, Caspar David. Der Wanderer über dem Nebelmeer. 1818. Pintura a óleo, 94,8 $\mathrm{cm} \times 74,8 \mathrm{~cm}$.

GANDY, Matthew. The Melancholy Observer: Landscape, Neo-Romanticism, and the Politics of Documentary Filmmaking. In: PRAGER, Brad (ed.). A Companion to Werner Herzog. Chichester: Willey-Blackwell, p. 528-546, 2012.

HALL, Jeanne. Don't you ever just watch? American Cinema Verité and Don't look back. In: GRANT, B. K; SLONIOWSKI, J. (org.). Documenting the Documentary: Close Readings of Documentary Film and Video. Detroit: Wayne State University Press, 2013.

HERZOG, Werner. Minnesota Declaration: Truth and Fact in Documentary Cinema (Lessons of Darkness). Minnesota, 30 Apr. 1999. Disponível em:

https://www.wernerherzog.com/complete-works-text.html\#2. Acesso em: 20 set. 2019.

HERZOG, Werner. On the Absolute, the Sublime, and Ecstatic Truth. Arion: a Journal of Humanities and the Classics, Boston, vol. 17, n. 3, p. 1-12, Winter 2010. Disponível em: https://www.bu.edu/arion/files/2010/03/Herzog.pdf. Acesso em: 20 set. 2019.

JOHNSON, Laurie Ruth. Forgotten Dreams: Revisiting Romanticism in the Cinema of Werner Herzog. New York: Camden House, 2016.

KANT, Immanuel. Crítica da faculdade do Juízo. Rio de Janeiro: Forense Universitária, 2008.

LONGINO, Dionísio. Do sublime. São Paulo: Martins Fontes, 1996. 
NAGIB, Lúcia. Werner Herzog: o cinema como realidade. São Paulo: Estação Liberdade, 1991.

O GRANDE êxtase do entalhador Steiner. Direção: Werner Herzog. Produção: Werner Herzog, Walter Saxer. Alemanha Ocidental, Werner Herzog Filmproduktion, 1974. Formato $16 \mathrm{~mm}$ (46 min), som. cor.

PAGANELLI, Grazia. Ekstase und Wahrheit. Ecstasy And Truth. Estasi e Verita. Film Edition Werner Herzog. München: Goethe-Institut, 2010.

PRAGER, Brad. Landscape of the mind: the indifferent earth in Werner Herzog's films. In: GRAEME, Harper; RAYNER, Jonathan (ed.). Cinema and Landscape: Film, Nation and Cultural Geography. Bristol: Intellect Books, 2010.

PRAGER, Brad. The Cinema of Werner Herzog: aesthetic ecstasy and truth. London: Wallflower press, 2007.

SCHAMA, Simon. Landscape and Memory. New York: Vintage Books, 1995.

SINAIS de vida. Direção: Werner Herzog. Produção: Werner Herzog. Roteiro: Werner Herzog. Música: Popol Vuh. Alemanha Ocidental, Werner Herzog Filmproduktion, 1968. Formato $35 \mathrm{~mm}$ (87 $\mathrm{min})$, som. p.b.

VERRONE, William. Transgression and Transcendence in the Films of Werner Herzog. FilmPhilosophy, Edinburgh, v. 15, n. 1, p. 179-203, 2011.

WRIGHT, Cesare. Re-Framing "Ecstatic Truth" Experiments in the New Visual Language of Werner Herzog. Dissertation (PhD in Philosophy) - Program in Visual \& Cultural Studies, University of Rochester, Rochester, 2016.

\title{
The Romantic Cinema of Werner Herzog: approaches between German Romanticism and the Concept of Ecstatic Truth
}

\begin{abstract}
This article explores the similarities between the intellectual movement German Romanticism and Werner Herzog's concept of Ecstatic Truth. We seek to single out, in the filmmaker's cinema, propositions of a romantic-influenced aesthetics. As methodology, we use direct sources related to the approach of "Theory of Filmmakers". In other words, besides film fragments, we also turned to interviews and declarations by Werner Herzog about the making of his films as a creation process. The main similarities found from this comparison were: (1) an inherently romantic tendency towards escapism, present among Herzog's characters; (2) nature seen as the only option left, and (3) moments filled with the sensation of fear, shiver and paralysis.
\end{abstract}




\section{Keywords}

German Romanticism. Ecstatic Truth. Werner Herzog. Cinema.

Recebido em 13/05/2019

Aceito em 01/07/2019 